\title{
Financiamiento de proyectos de infraestructura a través de fondos de inversión públicos: ¿una modificación pendiente?
}

\author{
Renzo Luna Urquizo \\ Ricardo Anaya Amaya
}

\begin{abstract}
Resumen.- Actualmente, los fondos de inversión públicos no pueden otorgar préstamos ni adquirir directamente certificados de cobro típicos de proyectos de infraestructura cofinanciados. Por supuesto, dicha limitación, que carece de sustento regulatorio, limita la participación de los fondos de inversión públicos como financistas de dichos proyectos $\mathrm{y}$, por ende, el desarrollo de los mismos. Se encuentra pendiente, por tanto, una modificación en la normativa aplicable a dichos vehículos.
\end{abstract}

Abstract.- Currently, public investment funds cannot provide loans or directly acquire typical certificates of collection from co-financed infrastructure projects. Evidently, such a limitation, which is devoid of regulatory support, restricts the capacity of public investment funds to act as financers of infrastructure projects. In turn, the development of these projects is also restricted. Therefore, a change in the regulations applicable to such investment vehicles is necessary. 


\section{Introducción}

El marco constitucional vigente promueve la participación activa de la inversión privada en la economía. Con ello, se reduce el rol del Estado al de un agente subsidiario. No obstante, dicho rol no impide que el Estado pueda colaborar con la iniciativa privada; tan así es que la legislación admite la actuación del Estado en proyectos de asociaciones público-privadas mediante el otorgamiento de cofinanciamientos. Esto último se condice con el rol de fomento hacia la actividad privada por parte del Estado. Para ello, la norma regula las condiciones mediante las cuales el Estado puede o no otorgar cofinanciamiento a proyectos de infraestructura y servicios públicos.

En la actualidad, es indiscutible la necesidad de formular e implementar nuevos proyectos de infraestructura para los próximos años, esto como consecuencia no solo de la evidente brecha en infraestructura existente en el país ${ }^{1}$, sino, además, por las obras de reconstrucción que se necesitarán desarrollar con motivo de los desastres naturales acontecidos en las costas peruanas a inicios de año. Urge, pues, fomentar mecanismos de financiamiento para dinamizar la ejecución de este tipo de obras.

En ese contexto, y en el marco del financiamiento que necesitarán los desarrolladores de los referidos proyectos de infraestructura, surgen como una alternativa interesante los fondos de inversión públicos y privados. Estos vehículos permiten canalizar los recursos de los inversionistas hacia múltiples horizontes y eventualmente deberían poder destinar esos recursos al sector infraestructura. Sin embargo, de una revisión inicial de la regulación actual se pueden identificar algunas restricciones para la inversión de los recursos de los fondos de inversión públicos en proyectos de infraestructura. En simple, no se permite que este tipo de fondos adquiera los certificados de cobro típicos para obras cofinanciadas ni que otorgue o invierta en préstamos o financiamientos que puedan ser requeridos por las sociedades concesionarias de un proyecto de infraestructura.

Ante esta situación, surge la interrogante respecto de la razón por la que existen estas limitaciones o barreras legales. Una primera aproximación nos llevaría a concluir que nos encontramos ante una ausencia de regulación, motivada en un desinterés del mercado o del ente regulador y supervisor del mercado de valores, la Superintendencia del Mercado de Valores ("SMV"). De este modo, la finalidad del presente artículo es no solo identificar el problema, sino poder plantear una solución o cambio regulatorio en las normas

1 "Efectividad de la inversión pública a nivel regional y local durante el período 2009-2014". Disponible en web: http://doc.contraloria.gob.pe/estudiosespeciales/estudio/2016/Estudio_Inversion_Publica.pdf. Consulta realizada el día 11 de noviembre de 2017. 
reglamentarias de los fondos de inversión públicos a efectos de dinamizar el apremiante desarrollo de proyectos de infraestructura pública, de forma que estos vehículos puedan realmente servir, por un lado, como una alternativa de inversión atractiva para los inversionistas que quieran participar del desarrollo del sector infraestructura $y$, de otro lado, como un mecanismo de financiamiento de los proyectos de infraestructura en el Perú, lo cual impactará positivamente en nuestra economía y desarrollo.

Considerando las aproximaciones generales antes señaladas, el presente artículo tiene por objeto abordar la problemática antes descrita, para lo cual presenta el siguiente esquema: primero, se echará un vistazo al esquema típico de los proyectos de infraestructura cofinanciados, incluyendo los instrumentos de financiamiento otorgados por el Estado. En segundo lugar, se detallará la regulación actual de los fondos de inversión públicos y privados, lo cual permitirá entender la naturaleza, características y funcionamiento de estos vehículos, así como comprender las oportunidades o debilidades existentes para que los fondos de inversión puedan financiar proyectos de infraestructura pública mediante ciertos mecanismos. Finalmente, se precisarán las conclusiones y recomendaciones.

\section{Una aproximación a los proyectos de infraestructura cofinanciados}

Bajo el régimen económico constitucional actual2, el Estado promueve la participación del sector privado en proyectos que le permitan asegurar la provisión de la infraestructura y servicios públicos necesarios, mediante mecanismos que garanticen una adecuada asignación de riesgos, así como la operación y el mantenimiento de estas obras por un largo plazo. Una de las principales modalidades de actuación de la inversión privada en proyectos de infraestructura son las Asociaciones Público-Privadas (las "APP").

En Perú, desde hace 20 años, existe un marco legal determinado, especial y específico para el desarrollo de proyectos bajo la modalidad de APP, originadas por iniciativa estatal o privada. Este marco legal se compone actualmente por el Decreto Legislativo Nº1224 de 2015, modificado mediante el Decreto Legislativo N¹251 de 2017 (en conjunto, “DL 1224") y su Reglamento, contenido en el Decreto Supremo N410-2015-EF, modificado por el Decreto Supremo N68-2017-EF (en conjunto, “Reglamento del DL 1224”).

El DL 1224 define a las APP conforme se detalla a continuación:

2 El marco constitucional y legal peruano promueve la inversión privada, la misma que se practica en una economía social de mercado. El Estado, por su parte, ostenta un rol subsidiario y promotor de la actividad privada en la economía. 


\section{Artículo 11.-}

11.1. Las Asociaciones Público Privadas son modalidades de participación de la inversión privada, en las que se incorpora experiencia, conocimientos, equipos, tecnología, y se distribuyen riesgos y recursos, preferentemente privados, con el objeto de crear, desarrollar, mejorar, operar o mantener infraestructura pública y/o promover servicios públicos bajo los mecanismos contractuales permitidos por el marco legal vigente. Las Asociaciones Público Privadas se originan por iniciativa estatal o iniciativa privada. (Subrayado agregado).

Asimismo, conforme al artículo 11 del Reglamento del DL 1224, se entienden como proyectos permitidos de ser ejecutados como APP los siguientes: provisión de infraestructura pública general, urbana, de recreación y cultural, penitenciaria, de riego, salud, educación, servicios públicos, servicios de interés social, prestación de servicios vinculados a la infraestructura pública o servicios públicos, sistema de recaudación de peajes y tarifas, investigación aplicada o innovación tecnológica ${ }^{3}$.

Por otro lado, las APP pueden ser cofinanciadas o autofinanciadas. Se centrará la atención únicamente en las APP cofinanciadas, en tanto se analizará la viabilidad legal de que los certificados de cobro (modalidad de cofinanciamiento, como se detallará a continuación) otorgados por el Estado puedan ser adquiridos por fondos de inversión. Asimismo, la modalidad de cofinanciamiento analizada será aquella realizada mediante compromisos firmes ${ }^{4}$, a diferencia de los compromisos contingentes o garantías (financieras o no financieras).

Las APP cofinanciadas requieren que el Estado aporte recursos que cubran parcialmente los costos de construcción, operación o mantenimiento de la obra. De lo contrario, el proyecto no sería lo suficientemente rentable para justificar la inversión privada, en tanto no garantizaría un retorno que asegura la recuperación de esta inversión 5 .

Conforme al artículo 13 del DL 1224, las APP son cofinanciadas cuando requieren cofinanciamiento $\mathrm{u}$ otorgamiento o contratación de garantías financieras o no financieras que tengan probabilidad de demandar cofinanciamiento. El Reglamento del DL 1224 define al cofinanciamiento como

3 Numerales 2 y 3 del artículo 11 del Reglamento del DL 1224. Tenemos como ejemplos de APP a la Línea 2 del Metro de Lima y la Carretera Longitudinal de la Sierra Tramo 2.

4 El artículo 27 del DL 1224 define a las obligaciones firmes de la siguiente manera: " $a$. Compromisos firmes: Son las obligaciones de pago de importes específicos o cuantificables a favor de su contraparte, correspondiente a una contraprestación por la realización de los actos previstos en el contrato de Asociación Público Privada".

5 Cfr. ZÚNIGA, Laura. "El Diseño Legal de las Concesiones Cofinanciadas en el Perú". En Revista de Derecho Administrativo, N¹6, 2016, p. 109. 
cualquier pago que utiliza recursos públicos, total o parcialmente, a cargo de la entidad para cubrir las obligaciones establecidas en el respectivo contrato 6. Cabe mencionar que el DL 1224, complementado por el Reglamento del DL 1224, establece las características para que un proyecto calce como una APP autofinanciada7.

\section{i. APPs: estructura del cofinanciamiento en proyectos de infraestructura}

En términos generales, los procesos de promoción de los proyectos de APP se desarrollan dentro del marco de las siguientes fases identificadas: planeamiento y programación, formulación, estructuración, transacción y ejecución contractual.

Si bien no es objeto de este trabajo profundizar en los alcances de las distintas etapas, resulta importante abordar puntuales aspectos de dos de las etapas. Así, tenemos que en la etapa de estructuración, se diseña el contrato APP: se realiza, entre otros, la estructuración económico-financiera, la asignación de riesgos y se determina el mecanismo de retribución, en caso corresponda. Por su parte, en la etapa de ejecución contractual, el privado al cual se le adjudicó el proyecto (y al cual se le otorga una concesión) se encargará de ejecutarlo ("Sociedad Operadora”). Durante esta etapa se brindará el cofinanciamiento estatal.

Lo primero que debe quedar claro es que la Sociedad Operadora puede financiar la ejecución de las obras o la operación y mantenimiento de la respectiva infraestructura de diversas maneras. Así, no existe un marco normativo que predetermine el esquema de financiamiento a usarse, sino que esto se definirá caso por caso en cada contrato.

Sin perjuicio de la utilización de los flujos de caja que genere o vaya a generar

6 Son recursos públicos los recursos del Estado o que administren las entidades comprendidas dentro del ámbito de aplicación del DL 1224, indistintamente de las fuentes de financiamiento, incluyendo, pero sin limitarse, a los recursos ordinarios, recursos provenientes de operaciones oficiales de crédito, recursos determinados, así como recursos directamente recaudados, tales como arbitrios, tasas, contribuciones, entre otros.

7 De conformidad con el artículo 13 del DL 1224 y el artículo 12 del Reglamento del DL 1224, las APP son autofinanciadas cuando el proyecto cuenta con capacidad propia de generación de ingresos, no requiere cofinanciamiento en los términos descritos anteriormente y cumple con las siguientes condiciones: (i) demanda mínima o nula de garantía financiera por parte del Estado, (ii) las garantías financieras son consideradas como mínimas si no superan el 5\% del Costo Total de Inversión y, en caso de proyectos que no contengan componente de inversión, dichas garantías no superan el 5\% del Costo Total del Proyecto; o (iii) las garantías no financieras tienen probabilidad nula o mínima de demandar cofinanciamiento, lo cual ocurre cuando la probabilidad de demandar cofinanciamiento no sea mayor al 10\% para cada uno de los primeros 5 años de vigencia de la cobertura de la garantía prevista en el contrato. 
en el futuro el propio proyecto, puede (i) recibir aportes de capital o préstamos de sus accionistas; (ii) recibir préstamos o financiamiento directo de terceros (bancos, entidades financieras, multilaterales o agencias gubernamentales, fondos de inversión, etc.); (iii) emitir obligaciones, como es el caso de los bonos (financiamiento directo); (iv) transferir derechos de cobro que puedan emanar de los contratos de APP, como es el caso de las acreencias a las que se ha obligado pagar el Estado en diversos proyectos cofinanciados; y (v) otros pagos que pueda recibir la Sociedad Operadora por parte del Estado en forma de cofinanciamiento.

Uno de los riesgos asociados a la ejecución de los proyectos de infraestructura es el riesgo de construcción ${ }^{8}$. En simple, si la obra no llegara a construirse, evidentemente, no podrá generar ingresos en el futuro. La Sociedad Operadora ejecuta la obra y, únicamente una vez culminada, contará con el derecho de cobrar aquellas tarifas o mecanismos de retribución que le permitirán recuperar los costos incurridos.

Asimismo, dada la especial complejidad de los contratos de APP, la continuidad del proyecto estará sujeta al cumplimiento de hitos. Si no se cumpliera con el cronograma de hitos acordado en el propio contrato, el Estado podrá resolverlo y el privado perderá la concesión. Por ello, en este tipo de operaciones, la Sociedad Operadora acreditará con anterioridad a la adjudicación del proyecto que cuenta con la capacidad técnica y económica (riesgo de lograr un cierre financiero) para ejecutar la obra en el tiempo establecido en el contrato.

Entonces, ¿cómo se suele mitigar este riesgo de construcción en el caso de proyectos cofinanciados? Como se indicó líneas arriba, las APP cofinanciadas requieren del cofinanciamiento o contratación de garantías financieras o no financieras que tengan probabilidad de demandar cofinanciamiento. En tal sentido, el Estado, por la propia naturaleza del contrato de APP (concesión), no necesita que se concluya toda la obra para asegurar el pago de un derecho de crédito. Así, el supervisor estatal verificará el cumplimiento de cada hito (porcentaje de la totalidad de la obra) y se otorgará a la Sociedad Operadora un derecho de cobro frente al Estado peruano por la parte que se ha construido. Los más usuales son los CRPAOs y CR-RPIs9, los mismos que analizaremos a en el siguiente acápite.

8 Este riesgo engloba a aquellos riesgos durante la ejecución de la obra, como la probabilidad de que esta no se llegue a culminar, así como a los sobrecostos o mayores plazos que se generan en el periodo de construcción. Cfr. A. MAIRAL, Héctor. "Los riegos en la financiación privada de proyectos públicos". En Revista de Derecho Administrativo, N¹3, 2013.

9 Estos instrumentos de pago están vinculados a riesgos inherentes únicamente a la etapa de construcción del proyecto, que es el riesgo analizado. Existe, por supuesto, otro tipo de certificados que mitigan los riesgos inherentes a la etapa de operación, como es el caso de los RPMO. 


\section{ii. Certificados de cobro: CRPAOs y CR-RPIs}

Si bien estos términos provienen de la autorregulación de las partes al momento de celebrar el contrato de APP, la práctica comercial ha reconocido el uso reiterado de determinadas figuras. La primera figura de amplio reconocimiento es el Certificado de Avance de Obra ("CAO"): se trata de un documento expedido por el Estado, de acuerdo a la evaluación y certificación del Avance de Obra (según lo establecido en cada contrato) ejecutado por la Sociedad Operadora. Asimismo, el término hito alude al avance de un porcentaje de la obra en un plazo determinado.

Gráfico 1: expedición de CAO por cada hito10

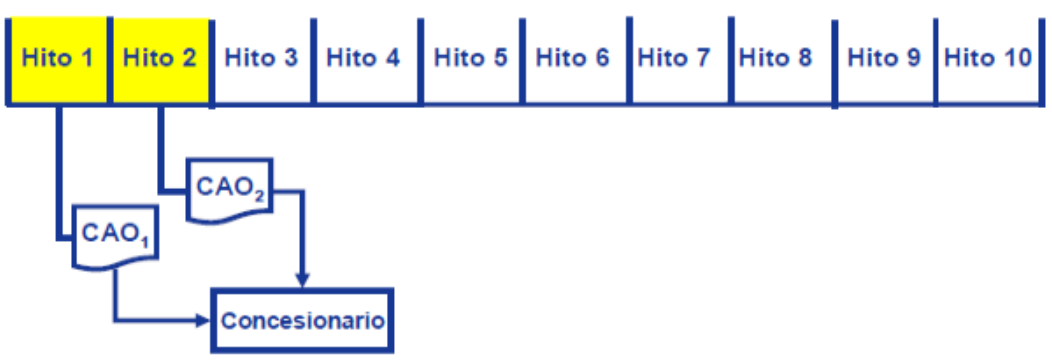

Al término de cada hito, la Sociedad Operadora recibirá un CAO, que acredita el cumplimiento de un determinado hito y genera el derecho a recibir un pago, bien sea del Pago por Avance de Obra ("PAO"), bien sea de la Retribución Anual por Inversión ("RPI")11, que son montos dinerarios, de acuerdo a la estructura de cada contrato de APP. Por su parte, los CRPAOs y CR-RPIs constituyen certificados de reconocimiento de derechos (acreencias) sobre los PAO y los RPI derivados de cada CAO expedido, respectivamente.

Finalmente, un RPICAO equivale al monto proporcional a la RPI derivado de cada CAO. De igual manera, un PAOCAO equivale al monto proporcional al PAO derivado de cada CAO. Son, pues, compromisos contractuales de pagar

10 Gráfico obtenido del Centro de Investigación de la Universidad del Pacífico (CIUP). Disponible en la web: http:/ / rubio.pe/Publicaciones/Proyectos\%20de\%20Inversi\%C3\%B3n.pdf. $\quad$ Consulta realizada el día 11 de noviembre de 2017.

11 "Los RPI constituyen un mecanismo de pago patrocinado por el Estado peruano por el cual la sociedad asegura el derecho a recibir un pago por los costos de construcción y mantenimiento asociados a la construcción del proyecto, a medida que hace entrega de las diferentes etapas del proyecto. Los RPI constituyen la obligación del Estado de pagar lo invertido por la sociedad en la implementación y puesta en operación del proyecto, lo que elimina el riesgo de construcción para los inversionistas". DE LOS HEROS, Juan Carlos y MARIN, Luis Ernesto. "Una Revisión al Project Finance". En Revista de Derecho Administrativo, $\mathrm{N}^{\circ} 16,2016$, p. 164. 
una fracción del RPI o PAO, respectivamente. Estos compromisos se materializan en los certificados mencionados: CRPAO y CR-RPI. Ciertamente, este tipo de certificados representativos de derechos de cobro poseen la misma lógica y naturaleza jurídica.

Estos derechos de cobro constituyen pagos incondicionales e irrevocables (efectos asimilables a una carta fianza), cuyo desembolso, sin embargo, se dará en una fecha posterior (pagos diferidos), de conformidad con el pacto del propio contrato de concesión. De esta manera, se mitiga parcialmente el riesgo de construcción, en tanto no tendrá que demostrarse que se ha construido toda la obra. Dicho certificado involucrará ahora la asunción de un riesgo soberano -equivalente al riesgo de que el Estado peruano efectivamente pague en la fecha programada- y ya no se asume el riesgo de que no se construya la totalidad del proyecto.

\section{Gráfico 2: ejemplo de CAO y CRPAO12}
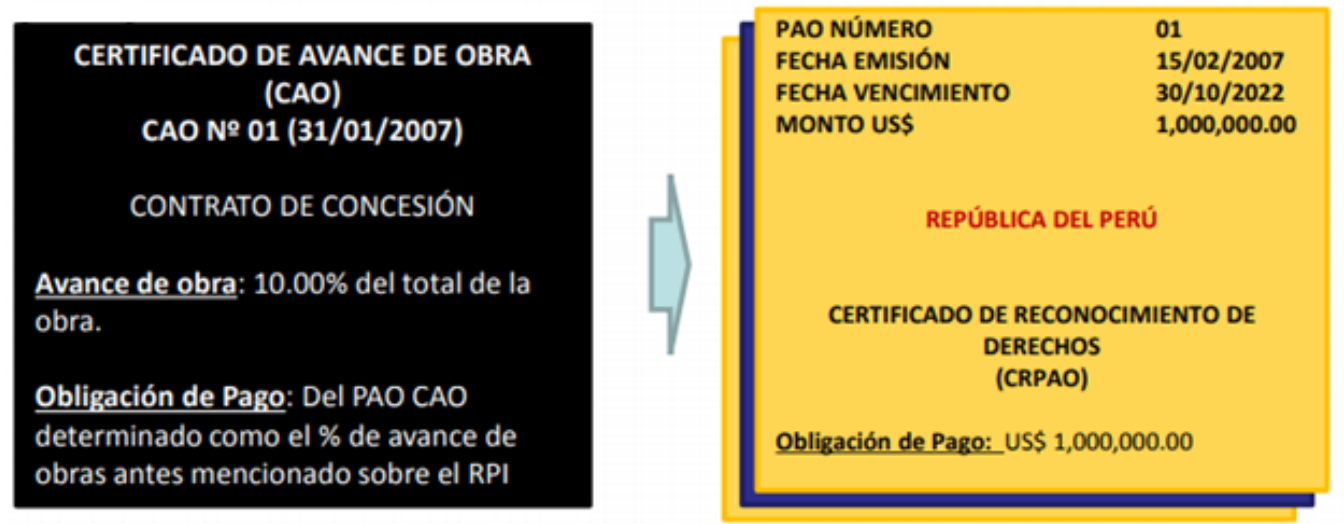

Las ventajas de este derecho de cobro son incuestionables. En primer lugar, la Sociedad Operadora ya no tendrá que soportar -al menos totalmente- el riesgo de construcción, en tanto una vez se acredite que se ha avanzado un porcentaje de la obra, se habrá generado una obligación de pago por parte del Estado. Únicamente estará pendiente que el Estado pague en la fecha pactada. Asimismo, se identifica que la naturaleza de estos certificados (cobro automático supeditado al paso del tiempo) permite estructurarlos como instrumentos de financiamiento frente a posibles inversionistas interesados en adquirirlos (como los fondos de inversión).

Más aún, el DL 1224 reconoce que los derechos de cobro derivados de los

12 "Estructuración Financiera de las APPs" (Presentación PPT). Disponible en web: http://www.proinversion.gob.pe/RepositorioAPS/0/0/EVE/TALLER_IP_CUSCO/ppt/Ya co\%20Rosas\%20_\%201.pdf . Consulta realizada el día 11 de noviembre de 2017. 
contratos de APP son libremente transferibles sin necesidad de autorización previa del Estado, salvo que, eventualmente, el contrato establezca una regulación diferente. Así, la Sociedad Operadora podría transferir estos certificados, por ejemplo, a los fondos de inversión, luego de aplicada la respectiva tasa de descuento ${ }^{13}$, para poder contar con los flujos necesarios para continuar con la ejecución del proyecto, sin tener que esperar la fecha de pago de cada certificado.

\section{iii. Estructuras de financiamiento actualmente viables}

Sin perjuicio de que en el siguiente punto se ahondará sobre los posibles instrumentos o activos en los que los fondos de inversión pueden efectuar sus inversiones, en los siguientes párrafos se mencionarán las principales estructuras por las cuales las Sociedades Operadoras obtienen el financiamiento necesario para el desarrollo de los proyectos de infraestructura.

La primera y más tradicional consiste en que las entidades financieras locales o extranjeras otorguen algún tipo de financiamiento o préstamo a la Sociedades Operadoras con el único objetivo de que pueda desarrollar el proyecto de infraestructura. Para lograr ello, la Sociedad Operadora se compromete a pagar el capital e intereses respectivos, estando estos últimos sujetos a la tasa que finalmente esté dispuesta a cobrar la entidad financiera.

El segundo es el referido a la inversión o adquisición de instrumentos de deuda emitidos por la Sociedad Operadora o por un vehículo de propósito especial (Special Purpose Vehicle, "SPV") al que le fueron transferidos determinados derechos de cobro o acreencias (por ejemplo, CRPAOs o CRPRPIs). De hecho, este fue el esquema de financiamiento utilizado en el proyecto cofinanciado de "Línea 2 y ramal Av. Faucett - Av. Gambetta de la Red Básica del Metro de Lima y Callao".

Para dicho proyecto, la estructura fue cofinanciada por el Estado mediante el pago irrevocable e incondicional de RPI-CAOs que representan el costo de la inversión en activos realizada por la Sociedad Operadora; así como mediante la retribución de parte de las obras a partir del sistema Pago por Obras ("PPO"), y parte de la provisión de Material Rodante a través del sistema Pago por Material Rodante ("PPMR"), a ser ejecutadas por la Sociedad Operadora.

El financiamiento por medio de los RPI-CAOs tuvo la siguiente estructura. Se colocaron bonos por la suma de USD 1,155 millones, a 19 años, con una tasa de

13 Tasa que refleja el costo de oportunidad del dinero invertido, que dependerá, entre otros, del nivel de riesgo, el plazo y el nivel de liquidez del activo en que se invierte. 
interés de $5.875 \%$ en el mercado internacional. Dichos bonos fueron emitidos por un SPV constituido en el exterior mediante una titulización internacional de los RPI-CAOs.

Gráfico 3: estructura de financiamiento a través de la titulización de RPI-CAOs y la posterior emisión de bonos en el mercado internacional14

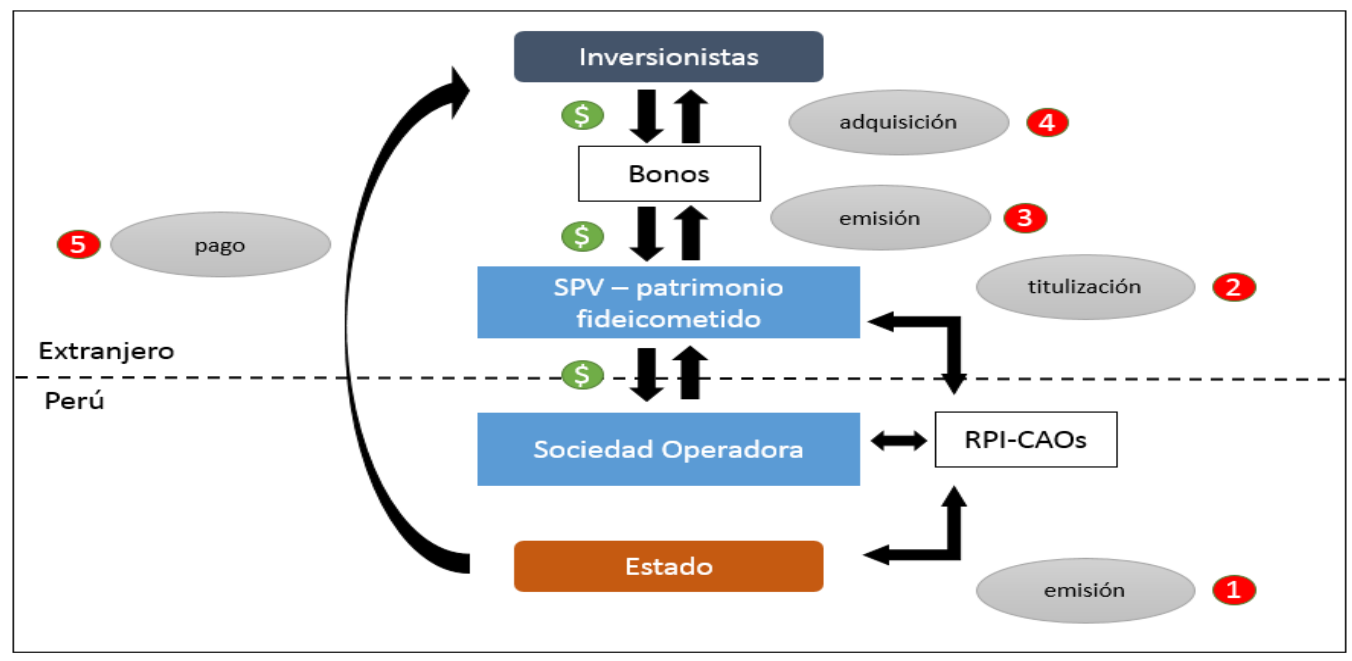

Por otro lado, es también posible la inversión o adquisición de instrumentos de deuda emitidos por un patrimonio fideicometido de titulización constituido mediante la transferencia de determinados derechos de cobro o acreencias (por ejemplo, CRPAOs o CRP-RPIs). Sin embargo, los altos costos que involucra la contratación de un ente fiduciario encarecería innecesariamente la estructura de financiamiento.

De este modo, los fondos de inversión, sean públicos o privados, pueden invertir en instrumentos representativos de deuda emitidos por (i) la Sociedad Operadora; (ii) por un SPV al que le fueron transferidos determinados derechos de cobro o acreencias (CRPAOs o CR-RPIs); o (iii) por un patrimonio fideicometido de titulización constituido mediante la transferencia de determinados derechos de cobro o acreencias (CRPAOs o CR-RPIs).

\section{iv. Lógica del financiamiento derivado de los certificados de cobro. Planteamiento del problema.}

La lógica de la estructura es la siguiente: la Sociedad Operadora necesita obtener flujos para poder ejecutar la obra $y$, una vez culminada, ponerla en marcha y así cubrir los costos incurridos durante el proceso de construcción. El Estado otorgará un certificado de crédito ante el cumplimiento de los hitos establecidos. Sin embargo, como se explicó en el punto II.2, estos certificados

14 Gráfico referencial. Elaboración propia. 
podrán ser cobrados únicamente cuando llegue la fecha de pago.

Sin embargo, la Sociedad Operadora requiere de flujos a medida que avanza con la obra para, precisamente, culminarla $\mathrm{y}$, una vez puesta en marcha, generar ingresos. Ante esta circunstancia, la Sociedad Operadora deberá transferir estos certificados de acreencias a un valor que refleje el valor presente de las acreencias (aplicada la tasa de descuento) para generar los flujos que demanda. En el punto anterior, se resumieron las alternativas de financiamiento que se han venido utilizado, con las desventajas detectadas, para distintos instrumentos de canalización de recursos, como los fondos de inversión.

Ahora bien, estas desventajas y costos adicionales inherentes a la complejidad de las estructuras explicadas podrían minimizarse si los fondos de inversión adquiriesen estos certificados directamente para financiar los proyectos de infraestructura. La pregunta es si dicha posibilidad resulta viable. Veamos.

\section{Fondos de Inversión: regulación actual}

Los fondos de inversión se encuentran regulados en la Ley de Fondos de Inversión y sus Sociedades Administradoras, aprobado mediante Decreto Legislativo N862-1996, y sus posteriores modificaciones ("Ley de Fondos de Inversión"). Dicha ley los define como aquellos patrimonios autónomos integrados por los aportes de personas naturales y jurídicas para su inversión en instrumentos, operaciones financieras y demás activos, bajo la gestión de una sociedad anónima denominada "sociedad administradora de fondos de inversión", por cuenta y riesgo de los partícipes.

El patrimonio del fondo de inversión se encuentra dividido en cuotas representadas en certificados de participación, los mismos que son transferibles y pueden adoptar la forma de títulos o anotaciones en cuenta. Asimismo, los fondos de inversión son de capital cerrado, caracterizándose porque su número de cuotas es fijo.

El funcionamiento y operaciones del fondo de inversión se sujetan a la Ley de Fondos de Inversión, al reglamento de la materia -en el caso de fondos de inversión cuyas cuotas de participación hayan sido colocadas por oferta pública, es decir, fondos de inversión públicos-, a su reglamento de participación y al contrato suscrito con el partícipe.

\section{i. Tipos de fondos de inversión}

Los fondos de inversión pueden clasificarse en fondos públicos o privados, 
según los certificados de participación sean colocados por oferta pública o por oferta privada.

\section{a. Fondos de inversión públicos}

Son aquellos fondos cuyos certificados de participación son colocados por oferta pública. De conformidad con lo señalado en el artículo 4 de la Ley del Mercado de Valores, cuyo texto único ordenado fue aprobado por Decreto Supremo N093-2002-EF, según ha sido modificada ("Ley del Mercado de Valores"), "se considera una oferta pública a aquella invitación adecuadamente difundida, que una o más personas naturales o jurídicas dirigen al público en general o a determinados segmentos de éste, para realizar cualquier acto jurídico referido a la colocación, adquisición o disposición de valores mobiliarios" (lo cual incluye certificados de participación).

De conformidad con el artículo 6 del Reglamento de Oferta Pública Primaria y de Venta de Valores Mobiliarios, aprobado por Resolución CONASEV N¹4198-EF/94.10, la definición antes señalada tiene los siguientes alcances: (i) invitación, (ii) adecuadamente difundida, (iii) público en general, (iv) segmento del público y (v) acto jurídico referido a la colocación o disposición de valores mobiliarios.

\section{b. Fondos de inversión privados}

Son aquellos fondos cuyos certificados de participación son colocados por oferta privada. Según lo dispuesto por el artículo 5 de la Ley del Mercado de Valores, se consideran ofertas privadas las siguientes:

- La oferta dirigida exclusivamente a inversionistas institucionales ${ }^{15}$. Los valores mobiliarios adquiridos por estos inversionistas no pueden ser

15 Son inversionistas institucionales, de conformidad con el Anexo 1 del Reglamento del Mercado de Inversionistas Institucionales, aprobado por Resolución SMV N021-2013SMV/01, los siguientes:

1. Los bancos, financieras y compañías de seguros y demás empresas señaladas por el artículo 16 de la Ley General del Sistema Financiero y del Sistema de Seguros y Orgánica de la Superintendencia de Banca y Seguros, Ley N²6702 y sus normas modificatorias; los agentes de intermediación; las administradoras privadas de fondos de pensiones; las sociedades administradoras de fondos de inversión; las sociedades administradoras de fondos mutuos y las sociedades titulizadoras.

2. Las entidades del exterior que desarrollen actividades similares a las señaladas en el numeral 1 y/o los Qualified Institutional Buyers a las que se refiere la Regla 144A de la $U$. S. Securities Act of 1933.

3. Las Entidades Prestadoras de Salud a las que se refiere la Ley de Modernización de la Seguridad Social en Salud, Ley N²6790, la Oficina de Normalización Previsional - ONP y el Seguro Social de Salud - Essalud.

4. Las personas jurídicas de derecho privado o de derecho público que tengan como una de sus actividades, de acuerdo con las disposiciones legales o convencionales que las rigen, la inversión en valores. En el caso de personas jurídicas no estatales, será exigible que 
transferidos a terceros, salvo que lo hagan a otro inversionista institucional, o se inscriba el valor previamente en el Registro Público del Mercado de Valores de la SMV ("RPMV”);

- La oferta de valores mobiliarios cuyo valor nominal o valor de colocación unitario más bajo sea igual o superior a S/487,165.75 o US\$150,360.00 aproximadamente. En este caso, los valores no pueden ser transferidos por el adquirente original a terceros con valores nominales o precios de colocación inferiores; y,

- Aquellas que establezca la SMV, institución encargada de la supervisión y el control del cumplimiento de la Ley del Mercado de Valores.

Considerando el tipo de inversionistas que pueden adquirir los certificados de participación de los fondos de inversión públicos, a diferencia de los inversionistas institucionales que invierten en los fondos privados, los cuales por su naturaleza, características o conocimientos, gestionan y evalúan adecuadamente los riesgos asociados a sus decisiones de inversión, la normativa peruana ha diferenciado el tratamiento de estos, estableciendo una regulación particular para los fondos de inversión públicos. Esto tiene como objetivo el tutelar a los inversionistas que participan en los mismos.

Así, como se indicó al inicio de este acápite, una de las principales diferencias entre los fondos de inversión públicos y privados es que los primeros se encuentran sujetos no solo a la Ley de Fondos de Inversión y su propio reglamento de participación, sino además a las normas de carácter general que ha aprobado la SMV -más específicamente, al Reglamento de Fondos de Inversión, aprobado mediante Resolución SMV N029-2014-SMV/01-, las mismas que establecen una serie de requisitos y procedimientos obligatorios a efectos de que un fondo público pueda constituirse y operar como tal.

Conforme se ha mencionado líneas arriba, los fondos de inversión privados, se encuentran menos regulados que los fondos de inversión públicos, motivo por el cual el procedimiento de su estructuración y constitución responde más a prácticas de mercado y se regula por los propios objetivos del gestor o administrador, así como para atender los intereses de los inversionistas que

cuenten con un portafolio de inversiones en valores igual o superior a un millón de Nuevos Soles (S/1,000, 000,00).

5. Los fondos y patrimonios autónomos administrados por las personas señaladas en los numerales anteriores, siempre que la decisión de inversión sea responsabilidad de ellas y que el patrimonio neto individual del fondo o patrimonio sea igual o superior a cuatrocientos mil Nuevos Soles (S/ 400 000,00).

6. Personas naturales que cuentan con un patrimonio superior a dos millones de Nuevos Soles (S/ 2,000, 000,00), y un portafolio de inversiones en valores igual o superior a un millón de Nuevos Soles (S/1,000, 000,00). 
invertirán sus recursos en el fondo.

No obstante, los requisitos mínimos exigidos en la Ley de Fondos de Inversión también son aplicables a los fondos de inversión privados. Tales requisitos son los siguientes: (i) los fondos de inversión deben ser de capital cerrado, el número de cuotas debe ser fijo y no es posible pactar la posibilidad de rescate antes de la liquidación del fondo, salvo que se trate de reembolsos derivados del ejercicio del derecho de separación del fondo que corresponde a los partícipes, (ii) deben contar con un reglamento interno o de participación, (iii) las inversiones podrán efectuarse en todo tipo de bienes y derechos según se establezca en el reglamento de participación y (iv) los fondos deben constituir una asamblea general de partícipes.

Sin duda, ambos tipos de fondos - públicos y privados- constituyen vehículos de inversión que podrían servir como fuentes de financiamiento para la ejecución de proyectos de infraestructura. Sin embargo, es necesario preguntarse si la legislación de la materia lo permite.

\section{ii. Viabilidad legal: ¿pueden los fondos de inversión financiar proyectos de infraestructura?}

Como se mencionó en el acápite II.3, los proyectos de infraestructura cofinanciados requieren de flujos para ejecutar el proyecto. Así, si bien el financiamiento del Estado es realizado mediante la entrega de certificados de acreencias, estos no podrán ser cobrados hasta que se cumpla el plazo establecido en los certificados. Ante esta necesidad de liquidez, conviene explorar el financiamiento por medios de fondos de inversión mediante los siguientes esquemas: (i) el otorgamiento de un financiamiento directo o cofinanciamiento a efectos de que la Sociedad Operadora puede obtener los recursos necesarios para el desarrollo del proyecto de infraestructura, y (ii) la adquisición por parte de un tercero de las acreencias o derechos de cobro, incluyendo el derecho de cobro derivado de los CRPAOs o CR-RPIs.

Sobre el particular, debe indicarse que, en general, la propia naturaleza de los fondos de inversión los habilita para invertir los recursos administrados, provenientes de los aportes de personas naturales y jurídicas, en instrumentos, operaciones financieras y demás activos, por cuenta y riesgo de los partícipes. No obstante, corresponde determinar la existencia de posibles restricciones que pudieran tener estos vehículos, en función a su naturaleza, regulación aplicable, o sus características, que les impedirían participar en el referido financiamiento, de conformidad con los esquemas (i) y (ii).

\section{a. Fondos de inversión privados}


Dada la flexibilidad que caracteriza a los fondos privados, no existe ninguna restricción legal para que un fondo de inversión privado pueda financiar proyectos de infraestructura, bien sea a través de la adquisición de acreencias o derechos de cobro derivados de los instrumentos de pago de obra, o bien mediante el otorgamiento de préstamos o financiamientos directos. Dicho financiamiento podrá implementarse en función a la política de inversión del fondo, establecida en su respectivo reglamento de participación, el mismo que, a su vez, podrá detallar los requisitos y condiciones en los que se efectuará la misma.

\section{b. Fondos de inversión públicos}

De conformidad con el artículo 27 de la Ley de Fondos de Inversión, complementado con el artículo 77 del Reglamento de Fondos de Inversión, los fondos de inversión públicos pueden invertir únicamente, entre otros, en los siguientes instrumentos:

- Valores mobiliarios e instrumentos financieros ${ }^{16}$ no inscritos en el RPMV, siempre que se cumplan con ciertas condiciones ${ }^{17}$.

- Valores mobiliarios emitidos o garantizados por el Estado, negociados en el Perú o en el extranjero.

- Instrumentos financieros emitidos por gobiernos, bancos centrales, y otras personas jurídicas de derecho público o derecho privado extranjeras, emitidos al amparo de leyes o normas distintas a la legislación peruana, los cuales deben cumplir con determinados requisitos18.

16 El literal j) del artículo 1 del Reglamento de Fondos de Inversión considera como "instrumentos financieros" a los títulos valores y otros instrumentos representativos del pasivo o patrimonio de una entidad.

17 Deben cumplirse las siguientes condiciones:

i- Deben haber sido emitidos bajo el amparo de la legislación peruana.

ii- El emisor o el garante de dichos valores o instrumentos financieros debe contar con estados financieros del último ejercicio y los estados financieros intermedios del último período. En los casos en que el obligado al pago sea diferente del emisor, el primero debe contar con dichos estados financieros. Los estados financieros deben ser elaborados de conformidad con las Normas Internacionales de información financiera vigentes internacionalmente.

iii- Los distintos tipos de valores o instrumentos financieros, así como las condiciones que deben cumplir los obligados al pago deben estar expresamente señalados en el reglamento de participación del fondo.

iv- La SAFI debe suscribir un convenio con el emisor a fin de que informe periódicamente sobre los hechos relevantes que ocurran en su gestión y que afecten su situación financiera o los derechos del Fondo. El convenio debe contemplar la obligación de poner a disposición de la SAFI la información financiera intermedia y anual a partir del ejercicio en que se realice dicha inversión.

18 Deben cumplirse los siguientes requisitos:

i. El reglamento de participación establecerá los tipos de instrumentos, características y condiciones que deben cumplir los emisores. En el caso de inversiones en instrumentos 
- Aportes de capital para la constitución de empresas, siempre que ello haya sido incluido en la política de inversiones del Fondo, señalándose el tipo de actividad que realizará la empresa, bajo determinados requisitos19.

- Operaciones de adquisición de derechos sobre acreencias originadas por una transacción comercial de compraventa o suministro de bienes o servicios. En dicha adquisición interviene la SAFI, quien actúa por cuenta del fondo y, de otra parte, una (01) persona jurídica obligada al pago de un importe dinerario en una fecha cierta y una (01) persona natural o jurídica acreedora de dicha obligación. En estos casos, la SAFI debe suscribir un contrato marco con la persona jurídica obligada al pago de las acreencias en el cual se establecerán determinadas condiciones contractuales mínimas 20 .

- Adquisición de carteras de crédito, para lo cual debe cumplir con determinadas condiciones ${ }^{21}$.

emitidos por fondos extranjeros, la política de inversiones debe señalar las características y condiciones que deben cumplir estos fondos.

ii. La información financiera debe ser elaborada de conformidad con las Normas Internacionales de información financiera vigentes internacionalmente.

iii. No tener limitaciones contractuales a su transmisibilidad.

19 El pacto social que se suscriba debe indicar como mínimo lo siguiente:

i. El plazo para que la sociedad a constituirse quede inscrita en el Registro Público. Vencido el plazo sin haberse obtenido la respectiva inscripción, se devolverán los aportes efectuados por la SAFI en representación del fondo.

ii. Mientras la sociedad no adquiera personería jurídica, los aportes de capital otorgados por la SAFI en representación del fondo no podrán ser retirados de la empresa bancaria o financiera en que se encuentren depositados salvo en el caso de devolución establecido en el numeral precedente.

iii. La SAFI debe suscribir un convenio con el emisor a fin de que informe periódicamente sobre los hechos relevantes que ocurran en su gestión y que afecten su situación financiera o los derechos del fondo. El convenio debe contemplar la obligación de poner a disposición de la SAFI la información financiera intermedia y anual a partir del ejercicio en que se realice dicha inversión. Los estados financieros deben ser elaborados de conformidad con las Normas Internacionales de información financiera vigentes internacionalmente.

20 El contrato marco establecerá como mínimo lo siguiente: (a) la obligación de la persona jurídica obligada al pago de las acreencias de proporcionar a la SAFI, previamente a la cesión de las acreencias, sus estados financieros anuales del último ejercicio. Debe contener la obligación de remitir la correspondiente información financiera anual, en tanto se mantenga dicha inversión en la cartera del fondo. La información financiera debe ser elaborada de conformidad con las NIIF, (b) una cláusula mediante la cual la empresa obligada al pago de las acreencias a ser cedidas se obligue a su pago una vez producida la cesión de acreencias a favor del fondo y no podrá invocar ninguna causal como fundamento para incumplir su obligación, y (c) el procedimiento de liquidación de la deuda que debe establecer como mínimo: la forma de determinación de la fecha de pago, el procedimiento a seguir ante la eventualidad de no pago en la fecha prevista, y descripción de supuestos en los que resulte de aplicación la mora, intereses y penalidades.

21 Deben cumplirse las siguientes condiciones: (a) El reglamento de participación del fondo debe contener las características y condiciones que debe cumplir las carteras de crédito y sus obligados al pago antes y después de la inversión, así como los procedimientos para su adquisición y cobranza, (b) debe contener las condiciones que debe cumplir el cedente. Contar con un contrato con el cedente de la cartera de crédito la cual debe observar lo establecido en el numeral anterior, (c) las operaciones de cesión de derechos sobre acreencias deben ser respaldadas por contratos elaborados de conformidad con la legislación nacional y 
- Otros valores, activos $\mathrm{u}$ operaciones que determine la SMV mediante normas de carácter general.

Conforme se puede apreciar, los fondos de inversión públicos no se encuentran habilitados por la regulación aplicable para (i) invertir en el otorgamiento de un financiamiento directo o cofinanciamiento a favor de la Sociedad Operadora, ni (ii) en la adquisición de acreencias o derechos de cobro derivados de instrumentos como CRPAOs o CR-RPIs.

La SMV, encargada de regular y supervisar a, entre otros, los fondos de inversión públicos, está investida, como todo órgano estatal, del principio de legalidad. Este principio admite la existencia de actos reglados y actos discrecionales. A diferencia de los actos reglados, mediante los actos discrecionales, los entes administrativos gozan de libertad para decidir sobre un asunto concreto, toda vez que la ley no predetermina con rigurosidad cómo debe actuar la administración. Sin embargo, los actos discrecionales deben apuntar siempre a satisfacer el interés público, siendo este el límite de aquellos.

Una manifestación de la discrecionalidad es la normativa, consistente en el arbitrio para ejercer la potestad de reglamentar leyes sin transgredirlas ni desnaturalizarlas (en el presente caso, nos referimos al Reglamento de Fondos de Inversión). Vemos, pues, que toda la regulación administrativa pública debe estar justificada, es decir, que toda interferencia del Estado sobre la esfera de los particulares debe estar respaldada por una razón objetiva que amerite dicha restricción (un interés público tutelado). De lo contrario, dicha vulneración será arbitraria y, por ende, vulnerará el principio de legalidad ${ }^{22}$.

En el caso específico de las limitaciones a los fondos de inversión públicos contempladas en el Reglamento de Fondos de Inversión, cabría preguntarse cuál es su fundamento. Al respecto, se observa que no existe justificación alguna para restringir (i) la inversión u otorgamiento de préstamos a favor de la Sociedad Operadora, ni (ii) la adquisición de acreencias o derechos de cobro derivados de los instrumentos típicos en este tipo de obras. Se trata, más bien, de una restricción involuntaria por parte del ente regulador, ante la falta de requerimiento de los agentes del mercado para habilitar la canalización de los recursos de los fondos de inversión públicos a dichas alternativas de inversión, lo cual limita injustificadamente la utilización de diversos esquemas de financiamiento en los proyectos de infraestructura pública.

En principio, se aprecia que un fondo de inversión privado podría constituir

suscritos por el cedente de tales derechos y la SAFI, y (d) los derechos sobre las acreencias materia de cesión deben ser libremente transferibles y contar con una fecha de pago.

22 Cfr. Tribunal Constitucional. Expediente N0090-2004-AA/TC. Fundamentos del 8 al 12. 
una alternativa eficiente para la estructuración de un financiamiento en proyectos de infraestructura, dado que, además de otras ventajas mencionadas, este fondo, a diferencia de uno público, cuenta con mucha flexibilidad en cuanto a inversión de los recursos. En concreto, podrá bien (i) otorgar un financiamiento directo a favor de la Sociedad Operadora o bien (ii) adquirir directa o indirectamente derechos de cobro representados en los CRPAOs, CR-RPIs u otros instrumentos de similar naturaleza. Sin embargo, como se ha mencionado, no está jurídica ni económicamente justificado restringir dicha posibilidad a los fondos de inversión públicos, considerando que estos vehículos atraen a muchos inversionistas que optan por los mismos, en tanto se encuentran supervisados por la SMV y reportan, entre otros, información financiera de forma pública, la cual es de fácil acceso por parte de los inversionistas.

En consecuencia, bajo la regulación actual, los fondos de inversión públicos únicamente podrían adquirir indirectamente dichos derechos de cobro, de acuerdo a las estructuras detalladas, sin existir una justificación válida para dicha restricción, sino que se trataría de una ausencia de regulación producto de la falta de requerimiento del mercado (sociedades administradoras de fondos de inversión e inversionistas).

La solución a este problema consiste en una modificación reglamentaria para permitir que los fondos de inversión puedan invertir o participar (i) del financiamiento o cofinanciamiento de proyectos de infraestructura con la participación de fondos de inversión públicos o (ii) en la adquisición de los certificados de acreencia típicos en proyectos de infraestructura.

\section{Conclusiones y recomendaciones}

Actualmente, un fondo de inversión público de deuda no puede otorgar préstamos a terceros, como es el caso de las Sociedades Operadoras, ni adquirir acreencias o derechos de cobro derivados de instrumentos típicos en proyectos de obra, como los CRPAOs o CR-RPIs, u otros valores de similar naturaleza. Esta restricción no cuenta con una justificación que la respalde. La consecuencia directa es la desaceleración de los tan necesarios proyectos de infraestructura pública, producto de barreras legales que entorpecen la facilitación de inversiones.

Los fondos de inversión públicos, a diferencia de los privados, únicamente podrían adquirir dichos derechos de cobro de manera indirecta. Las modalidades actuales comprenden el invertir en instrumentos representativos de deuda emitidos por la Sociedad Operadora, por un SPV o por un patrimonio fideicometido de titulización al que le fueron transferidos determinados derechos de cobro o acreencias. 
Financiamiento de proyectos de infraestructura a través de fondos de inversión públicos: ¿una modificación pendiente?

Ante este problema, se recomienda promover una modificación o precisión normativa al Reglamento de Fondos de Inversión por parte de la SMV, que contemple la posibilidad de que un fondo de inversión público pueda otorgar préstamos a sociedades encargadas del desarrollo de proyectos de infraestructura o que se le permita la adquisición de acreencias o derechos de cobro derivados de los certificados emitidos por el Estado. 